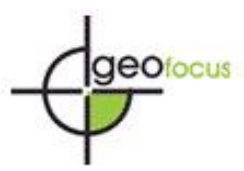

Guerrero, JVR., Moschini, LE., Chaves, MED., Mataveli, GAV., Morato, RG, Kawakubo, FS. (2020). Abordagem GEOBIA para a análise da dinâmica do uso da terra e cobertura vegetal no município de BrotasSP, Brasil. GeoFocus, Revista Internacional de Ciencia y Tecnología de la Información Geográfica, 26, 21-41. http://dx.doi.org/10.21138/GF.675

\title{
ABORDAGEM GEOBIA PARA A ANÁLISE DA DINÂMICA DO USO DA TERRA E COBERTURA VEGETAL NO MUNICÍPIO DE BROTAS-SP, BRASIL
}

\author{
${ }^{1 \mathrm{a} J O A ̃ O ~ V I T O R ~ R O Q U E ~ G U E R R E R O ~(D) ~}{ }^{1 \mathrm{~b}}$ LUIZ EDUARDO MOSCHINI (D),${ }^{2} \mathrm{MICHEL}$ \\ EUSTÁQUIO DANTAS CHAVES DE \\ ${ }^{3 e}$ RUBIA GOMES MORATO (D) ${ }^{3 f}$ FERNANDO SHINJI KAWAKUBO (D) \\ ${ }^{1}$ Departamento de Ciências Ambientais (DCAm). Universidade. Federal de São Carlos \\ Rodovia Washington Luís, km 235 - SP-310 São Carlos - São Paulo - Brasil CEP 13565-905 \\ ${ }^{2}$ Divisão de Observação da Terra e Geoinformática. Instituto Nacional de Pesquisas Espaciais. \\ Av. dos Astronautas, 1.758 - Jardim da Granja, São José dos Campos - SP, 12227-010, Brazil \\ ${ }^{4}$ Departamento de Geografia. Universidade de São Paulo \\ Av. Prof. Luciano Gualberto - Butantã, São Paulo - SP, 05344-020, Brazil

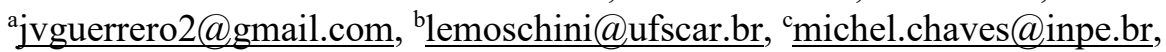 \\ dguilhermemataveli@gmail.com, ${ }^{\mathrm{e}}$ rubiagm@gmail.com,, fsk@usp.br
}

\section{RESUMO}

Diante do paradoxo entre a importância e a fragilidade dos recursos naturais, a preocupação com as formas de intervenção antropogênica no meio ambiente cresceu. Esse fator expandiu a busca por informações detalhadas da superfície terrestre, popularizando o uso de técnicas de sensoriamento remoto e processamento digital de imagens de satélite para a obtenção de tais informações em tempo hábil e com baixo custo. No Brasil, apesar da lacuna do acesso à tecnologia, diversas instituições utilizam sensoriamento remoto para o planejamento e o monitoramento ambiental. Entretanto, apesar do avanço tecnológico, o raciocínio e a percepção sobre a dinâmica da intervenção humana são, muitas vezes, empíricos, mesmo em municípios que possuem cultura voltada ao ecoturismo e à conservação de recursos naturais. $\mathrm{O}$ presente trabalho teve como objetivo analisar as alterações antropogênicas diretas e indiretas no uso da terra e cobertura vegetal entre 2001 e 2016 no município de Brotas-SP (Brasil), visando avaliar a efetividade de políticas públicas para o desenvolvimento municipal pautado em bases sustentáveis. Foi aplicada a abordagem GEOBIA para a classificação de imagens Landsat 7/ETM+ e Landsat 8/OLI com base em geoobjetos. Os resultados apontam a conversão de áreas de pastagem para agricultura e áreas naturais, em função do ecoturismo, porém, de forma fragmentada. A exatidão global do mapeamento foi de $90 \%$ e o índice Kappa de 0,89.

Palavras-Chave: análise temporal; uso e cobertura da terra; recursos naturais; diagnóstico ambiental; restauração florestal 
Guerrero, JVR, Moschini, LE., Chaves, MED., Mataveli, GAV., Morato, RG, Kawakubo, FS. (2020). Abordagem GEOBIA para a análise da dinâmica do uso da terra e cobertura vegetal no município de Brotas-SP, Brasil. GeoFocus, Revista Internacional de Ciencia y Tecnología de la Información Geográfica, 26, 21-41. http://dx.doi.org/10.21138/GF.675

\section{USE OF GEOBIA APPROACH FOR ANALYSING THE LAND USE AND VEGETATION COVER DYNAMICS IN THE MUNICIPALITY OF BROTAS-SP, BRAZIL}

\section{ABSTRACT}

Given the importance and fragility of natural resources, the concern with the disorderly human intervention on the environment has become recurrent, and different approaches for space occupation are being implemented. However, perception and detection of spatial changes are often empirical due to the lack of information. Thus, the best possible information regarding land use and vegetation cover is needed to improve understanding such changes in the Earth's surface and their dynamism. The present work aimed at analysing the anthropogenic changes on land use and vegetation cover between 2001 and 2016 in the municipality of Brotas-SP (Brazil), where there is a recent focus on ecotourism and the conservation of natural resources, especially for evaluating the effectiveness of public policies for municipal development based on sustainable bases. The GEOBIA object-oriented image classification approach was applied to Landsat 7/ETM+ and Landsat 8/OLI images. Land use and vegetation cover maps showed the conversion of pasture areas to agriculture and natural areas, as a function of ecotourism, however, in a fragmented way. The overall accuracy and Kappa index of the classified maps was $90 \%$ and 0.89 , respectively, proving the efficiency of this approach in environmental studies.

Keywords: temporal analysis; land use and cover; natural resources; environmental diagnosis; forest restoration.

\section{Introdução}

O município de Brotas (Brasil) é considerado referência nacional no contexto de recuperação ambiental e conservação dos recursos naturais e dos mananciais de abastecimento de água, sendo o principal motivo para isto a adoção de políticas públicas para a restauração de áreas florestais (Batista \& Gastmans 2015; Silva et al. 2016; Trevisan et al. 2017). Atrelado a isso, a possibilidade de utilizar as riquezas naturais como fonte de geração de divisas, por meio do ecoturismo, coloca Brotas como expoente na questão ambiental. Apesar da tentativa de reorganização espacial para a exploração do ecoturismo, estudos recentes apontaram a existência de apenas 17,7 \% de remanescentes florestais no município (Ronquim et al. 2018), bem como 32,09\% das áreas de preservação permanente ocupadas inadequadamente e $68,45 \%$ da área total classificada com prioridade alta a muito alta à restauração (Silva et al. 2016). Esse cenário pode inviabilizar a tentativa de geração de divisas pelo ecoturismo em curto prazo.

Tal situação indica a necessidade de melhorar o planejamento e a adequação à legislação por parte dos órgãos públicos responsáveis (Silva et al. 2016). Uma informação vital para os tomadores de decisão, e que pode auxiliar neste processo, é a de uso da terra e cobertura vegetal e de suas mudanças ao longo do tempo (Guerrero et al. 2020), que são capazes de influenciar aspectos sociais e ambientais, como a regulação climática, o ciclo do carbono, a qualidade e disponibilidade da água e a biodiversidade (Yu et al. 2016). 
Guerrero, JVR, Moschini, LE., Chaves, MED., Mataveli, GAV., Morato, RG, Kawakubo, FS. (2020). Abordagem GEOBIA para a análise da dinâmica do uso da terra e cobertura vegetal no município de Brotas-SP, Brasil. GeoFocus, Revista Internacional de Ciencia y Tecnología de la Información Geográfica, 26, 21-41. http://dx.doi.org/10.21138/GF.675

O sensoriamento remoto tem se apresentado como forma eficiente de registrar as mudanças no uso da terra e na cobertura vegetal ao longo do tempo e quantificar estas informações, constituindose como ferramenta essencial para levantamento de dados científicos e modelagem de processos naturais (Jensen 2009), o que é essencial para o direcionamento de ações de planejamento territorial. Entre as diversas técnicas de obtenção de informações da paisagem via sensoriamento remoto está a abordagem de classificação orientada a objetos Geographic object-based image analysis (GEOBIA) (Hay \& Castilla 2008), que vem sendo recentemente explorada para monitorar, planejar ações e gerir o território de forma otimizada (Blaschke et al. 2014; Csillik et al. 2019). Seu grande diferencial reside na possibilidade de incorporar a informação contextual presente no conjunto de pixels da imagem, analisando a resposta espectral dos pixels, e outros atributos importantes para reconhecimento das classes, como textura, cor, tamanho e forma, procurando reproduzir o raciocínio humano (Chen et al. 2012, Ye et al. 2018).

Com a intensificação da aplicação de séries temporais provenientes de sensores a bordo dos satélites da série Landsat, houve aumento no uso de objetos geográficos para melhorar a detecção de mudanças de uso e cobertura da terra (Chaves et al. 2020), substituindo, em casos específicos, a abordagem baseada em pixels (Blaschke et al. 2014). Alguns autores apontam que a tradicional abordagem baseada em objetos usando imagens com especificações semelhantes às da série Landsat (aproximadamente 30 metros de resolução espacial) fornece resultados mais detalhados do que as abordagens baseadas em pixels para mapear áreas urbanas (Lefebvre et al. 2016; Toure et al. 2018), agrícolas (Ma et al. 2017; Belgiu \& Csillik 2018) e naturais (Silveira et al. 2019), por fornecer melhores desempenhos nas classificações e por mitigar o efeito granular conhecido como "salt-andpepper" (Jiang et al. 2015; Belgiu \& Csillik 2018). Ye et al. (2018) mostraram que a GEOBIA aumenta a exatidão de classificações por três motivos: (i) minimiza a variabilidade espectral dentro da classe atribuindo todos os pixels no objeto a uma mesma classe; (ii) faz melhor uso das informações espaciais implícitas nas imagens detectadas remotamente, como tamanho, forma e textura dos objetos; e (iii) facilita a integração de relações contextuais e semânticas entre objetos geográficos.

Diante do exposto, o objetivo deste trabalho consistiu em quantificar e analisar, por meio da abordagem GEOBIA, as mudanças no uso da terra e cobertura vegetal transcorridas no município de Brotas-SP (Brasil), entre os anos de 2001 e 2016, focando em identificar as tendências de mudanças e a eficiência dos programas ambientais adotados para a restauração da vegetação natural local.

\section{Materiais, dados e método}

\section{1. Área de estudo}

O município de Brotas está localizado na região central do estado de São Paulo (Brasil), pertencendo à mesorregião de Piracicaba e distanciando-se $235 \mathrm{~km}$ da capital São Paulo (Figura 1). 


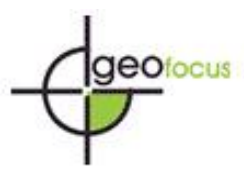

Guerrero, JVR, Moschini, LE., Chaves, MED., Mataveli, GAV., Morato, RG, Kawakubo, FS. (2020). Abordagem GEOBIA para a análise da dinâmica do uso da terra e cobertura vegetal no município de Brotas-SP, Brasil. GeoFocus, Revista Internacional de Ciencia y Tecnología de la Información Geográfica, 26, 21-41. http://dx.doi.org/10.21138/GF.675

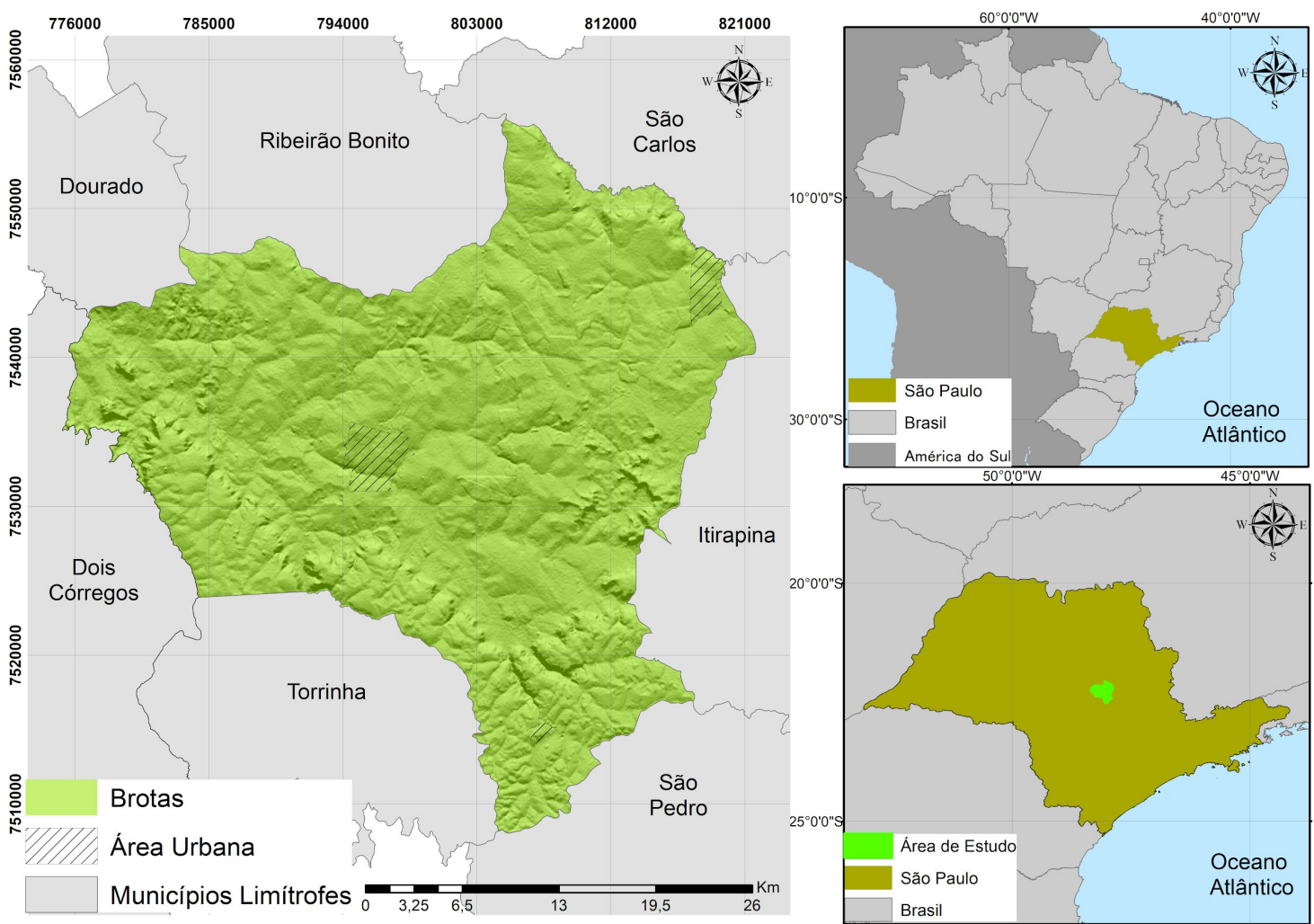

Figura 1. Mapa de Localização da área de estudo, o município de Brotas-SP, Brasil. Fonte: Autores (2020).

De acordo com a classificação de Köppen, o clima na área de estudo é o Tropical, caracterizado por apresentar temperatura média anual de $22^{\circ} \mathrm{C}$ e índice pluviométrico anual variando entre 1.300 mm e 1.400 mm (Köppen 1936; Álvares et al. 2013). A geomorfologia local é composta por cuestas basálticas e relevos que variam de plano a ondulado, enquanto a geologia é composta por rochas intrusivas básicas (basalto) e arenitos (Peixoto 2010; Prefeitura Municipal de Brotas 2016). Quanto à vegetação, o município apresenta algumas áreas de Cerrado, porém a vegetação natural encontra-se muito suprimida em função do histórico de intensa atividade agrícola (Rudorff et al. 2010; Trevisan \& Moschini 2015).

Em termos de atividades que impactam o uso da terra e cobertura vegetal em Brotas, ressalta-se a produção agrícola, especialmente pela forte presença de cafeicultura, citricultura, silvicultura de eucalipto e cana-de-açúcar, bem como o crescimento recente de atividades de ecoturismo aliado à preservação dos recursos naturais como forma de apresentar um desenvolvimento mais sustentável na região (Prefeitura Municipal de Brotas 2016). Como consequência, o município é impactado, desde a década de 1920, com o alto grau de apropriação do meio e seus recursos por meio da agricultura e turismo (Prefeitura Municipal de Brotas 2006). Este processo de uso e ocupação da terra, pautado na adoção de um modelo insustentável em termos de manutenção dos recursos naturais existentes, que 
Guerrero, JVR, Moschini, LE., Chaves, MED., Mataveli, GAV., Morato, RG, Kawakubo, FS. (2020). Abordagem GEOBIA para a análise da dinâmica do uso da terra e cobertura vegetal no município de Brotas-SP, Brasil. GeoFocus, Revista Internacional de Ciencia y Tecnología de la Información Geográfica, 26, 21-41. http://dx.doi.org/10.21138/GF.675

se baseia em monoculturas, manejo inadequado por falta de planejamento e instabilidade econômica, causou fragmentação florestal e afetou a dinâmica ambiental no município (Ferraz et al. 2009).

\subsection{Materiais}

Para a realização deste trabalho foram utilizadas duas imagens orbitais dentro de um intervalo de quinze anos (2001 - 2016). A imagem do ano de 2001 foi obtida em 07/06 pelo sensor Enhanced Thematic Mapper Plus (ETM+) do Landsat 7 com resolução espacial de 30 metros (15 metros para a banda pancromática) e 8 bits de resolução radiométrica. Já para 2016, a imagem de 28/06 foi obtida pelo sensor Operational Land Imager (OLI) a bordo do Landsat 8, com as mesmas resoluções espaciais descritas anteriormente e 16 bits de resolução radiométrica.

As duas imagens selecionadas são do mesmo período do ano a fim de garantir uma menor variabilidade de brilho decorrente das mudanças no ângulo de elevação solar e de azimute. Além disto, tal procedimento também foi importante para evitar possíveis interpretações equivocadas decorrentes das mudanças fenológicas da vegetação, bem como do calendário agrícola. As bandas utilizadas cobrem os intervalos de comprimento de onda do verde, vermelho, infravermelho próximo e o pancromático. A seleção dessas bandas baseou-se no contraste espectral observado entre os diferentes tipos de uso da terra e cobertura vegetal da área de estudo. Ambas imagens foram adquiridas gratuitamente no site do United States Geological Survey - USGS (http://glovis.usgs.gov) já corrigidas geometricamente, a partir de pontos de controle do Global Land Survey (GLS) e dados de elevação do terreno do Shuttle Radar Topography Mission (SRTM) (USGS 2020), e radiometricamente.

\subsection{Método}

Os procedimentos metodológicos para o mapeamento da dinâmica da cobertura vegetal e uso da terra na área de estudo consistiram na utilização de técnicas de sensoriamento remoto e processamento digital de imagens, a partir da aplicação da classificação orientada a objetos. Inicialmente, ambas as imagens foram realçadas para melhorar o contraste e os detalhes geométricos dos diferentes tipos de uso da terra e cobertura vegetal. Após o realce, foram geradas duas composições coloridas, sendo uma para cada imagem utilizada, a partir das bandas dos canais verde, vermelho e infravermelho próximo (bandas 2, 3 e 4 do sensor ETM+ e 3, 4 e 5 do sensor OLI). Com o objetivo de aumentar o detalhamento geométrico do mapeamento, as composições coloridas foram fusionadas com a banda pancromática, que possui resolução espacial mais fina (15 metros). Para tal, foi empregada a técnica da transformação do espaço de cores RGB (Red, Green e Blue) para o espaço IHS (Intensity, Hue e Saturation) (Carper et al. 1990). A fusão de imagens envolveu três etapas: (i) cálculo de intensidade, matiz e saturação a partir de uma composição colorida RGB; (ii) substituição da componente intensidade pela banda pancromática de alta resolução; e (iii) reversão do espaço IHS para o RGB.

A comparação visual e qualitativa das composições anteriores e posteriores à fusão permitiu constatar que este processo melhorou o detalhamento geométrico das feições a serem classificadas, incluindo aquelas cujas características são similares, como "Agricultura" e "Campo/Pastagem", o que potencializou a distinção de classes por meio do classificador. Em termos de características espectrais, ressalta-se que a aplicação da fusão de imagens não causou alterações significativas no 
Guerrero, JVR, Moschini, LE., Chaves, MED., Mataveli, GAV., Morato, RG, Kawakubo, FS. (2020). Abordagem GEOBIA para a análise da dinâmica do uso da terra e cobertura vegetal no município de Brotas-SP, Brasil. GeoFocus, Revista Internacional de Ciencia y Tecnología de la Información Geográfica, 26, 21-41. http://dx.doi.org/10.21138/GF.675

comportamento espectral das classes, e, portanto, não interferiu na integridade dos dados espectrais de entrada para efetuar as classificações.

Após a aplicação da técnica de fusão de imagens, iniciou-se a etapa de segmentação. Foi adotado para tal o algoritmo não-paramétrico de agrupamento Meanshift, (Fukunaga \& Hostetler 1975), que procura estimar as modas (máximas) de uma função de densidade de probabilidade. Estas modas de funções de densidade são empregadas para solucionar diversos problemas de machine learning, dentre eles, a segmentação de imagens (Ghassabeh \& Rudzicz 2016). As imagens analisadas foram convertidas em pontos dentro de um espaço amostral. Em seguida, nuvens de pontos foram identificadas e agrupadas por meio da estimativa de densidade Kernel, com cada nuvem representando um segmento.

Os valores dos parâmetros de segmentação utilizados apresentam diferenças de uma data para a outra, devido às características particulares de cada imagem e dos diferentes sensores utilizados (Tabela 1). Tais parâmetros foram definidos a partir de testes prévios e sua aderência às características das imagens. Ressalta-se que a seleção de parâmetros de segmentação ainda é, comumente, pautada em testes de tentativa e erro, pois cada imagem possui características específicas (Toure et al. 2016; Watkins \& Van Niekerk 2019). Os segmentos foram gerados a partir de três parâmetros principais: (i) detalhe espectral (nível de separação espectral entre objetos, visando diminuir o total de segmentos ou aumentar a separação de alvos espectralmente parecidos); (ii) detalhe espacial (que define a proximidade entre os atributos da imagem); e (iii) tamanho mínimo do segmento (que funde os segmentos menores que o valor atribuído) (ESRI 2016), definidos com base em testes, visando o equilíbrio entre a detecção de feições e a diminuição de segmentos (Mataveli et al. 2018; de Oliveira et al. 2020).

Tabela 1. Parâmetros utilizados para a segmentação das imagens classificadas: Detalhe espectral (nível de separação espectral entre objetos), Detalhe Espacial (proximidade entre os atributos da imagem) e Tamanho Mínimo do Segmento (fusão de segmentos menores). Todos os parâmetros são adimensionais e foram determinados por meios de testes prévios aplicados às imagens classificadas.

\begin{tabular}{ccc}
\hline Parâmetro & $\begin{array}{c}\text { Imagem } \\
\text { Landsat 7/ETM+ } \\
(2001)\end{array}$ & $\begin{array}{c}\text { Imagem } \\
\text { Landsat 8/OLI } \\
(2016)\end{array}$ \\
\hline Detalhe Espectral & 20 & 16 \\
Detalhe Espacial & 6 & 7 \\
Tamanho Mínimo do Segmento & 6 & 7 \\
\hline
\end{tabular}

Fonte: Autores (2020).

O último processo para o mapeamento do uso da terra e cobertura vegetal foi a classificação das imagens previamente segmentadas. Este processo consistiu em coletar amostras (segmentos) de treinamento correspondentes aos tipos de uso encontrados na área e aplicar um algoritmo para a classificação dos geo-objetos. Foram coletadas 100 amostras para cada tipo de uso da terra e cobertura vegetal, número de amostras definido por de Oliveira et al. (2020) em estudo semelhante, de forma estratificada, aleatória e por meio de inspeção visual, onde a definição das classes a que pertencem os segmentos respondeu à seguinte regra de classificação: "Agrícola" (referentes às culturas agrícolas anuais e perenes), "Água" (corpos d'água que cortam o município), "Campo/Pastagem" (áreas 


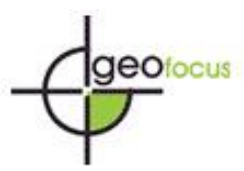

Guerrero, JVR, Moschini, LE., Chaves, MED., Mataveli, GAV., Morato, RG, Kawakubo, FS. (2020). Abordagem GEOBIA para a análise da dinâmica do uso da terra e cobertura vegetal no município de Brotas-SP, Brasil. GeoFocus, Revista Internacional de Ciencia y Tecnología de la Información Geográfica, 26, 21-41. http://dx.doi.org/10.21138/GF.675

destinadas ao pasto, tanto para pousio de terras quanto para a criação de gado), "Eucalipto" (áreas florestadas não-naturais, plantadas com eucalipto), "Mata" (áreas naturais florestadas, especialmente com vegetação nativa), "Solo exposto" (áreas nas quais o solo está em exposição causada por erosões naturais e ações antropogênicas) e "Urbano" (malha urbana do município de Brotas).

As classificações dos geo-objetos foram feitas com a utilização do classificador Máxima Verossimilhança, proposto por Swain \& Davis (1978). A fim de avaliar a acurácia do mapeamento e validar a efetividade da metodologia utilizada para as classificações do uso da terra e cobertura vegetal, foram produzidas matrizes de erros (Congalton 1991), para as quais foram coletadas 50 amostras de referência provenientes de imagens de alta resolução espacial do Google Earth ${ }^{\circledR}$ para cada classe de uso da terra e cobertura vegetal. As amostras de referência foram confrontadas com os resultados da classificação, gerando coeficientes de concordância entre estes dois conjuntos de dados, como o coeficiente Kappa (Landis \& Koch 1977), a exatidão global e a exatidão do produtor.

Os resultados da aplicação do índice Kappa variam entre valores de 0 a 1 , sendo zero um indicativo de nenhuma concordância e 1 indicando a total concordância entre os dados de referência e os resultados do mapeamento. Os resultados referentes aos valores Kappa consideraram os níveis categóricos de concordância propostos por Landis \& Koch (1977), já que tais níveis categóricos permitem verificar a qualidade dos mapeamentos.

\section{Resultados e discussão}

\subsection{Segmentação das imagens Landsat}

Conforme descrito, diferentes valores adotados nos parâmetros da segmentação geraram diferentes resultados de acordo com os atributos presentes da imagem. Como forma de exemplificar este processo, a Figura 2 mostra o resultado da segmentação adotando parâmetros que ilustram a falta e o excesso de segmentos gerados. Como pode ser observado, valores baixos para o detalhe espectral resultam em uma segmentação com poucos detalhes, tornando a imagem demasiadamente homogênea. Por outro lado, valores altos resultam no excesso de particionamento da imagem.
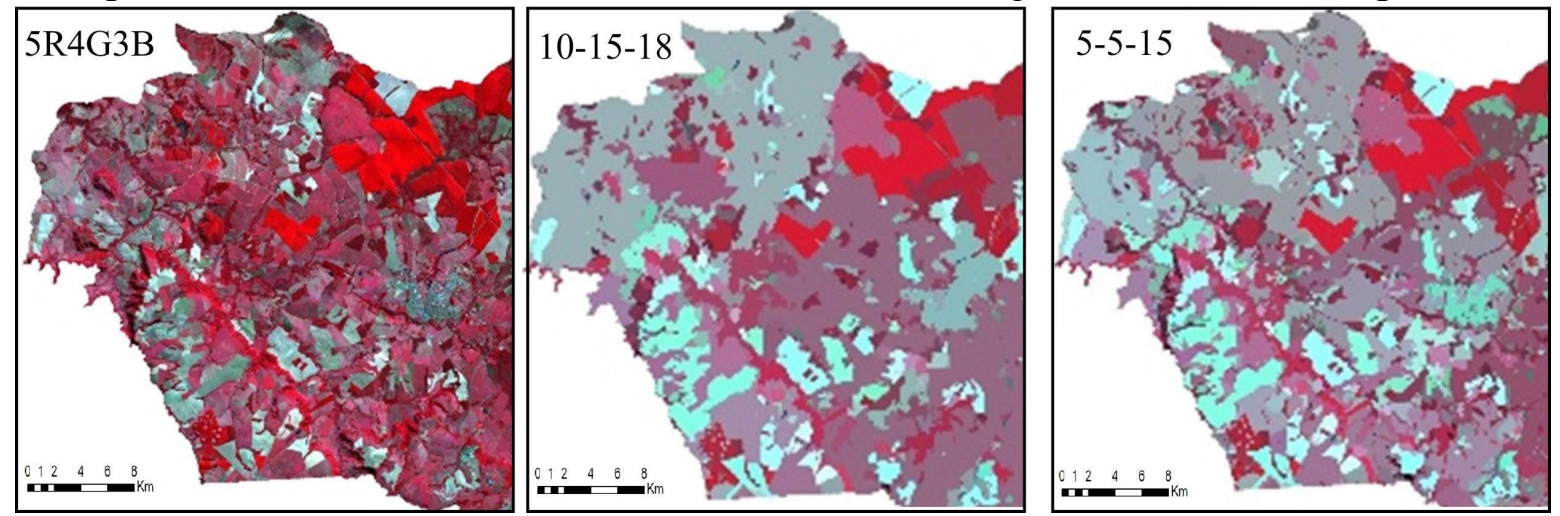

Figura 2. Resultado da segmentação para diferentes parâmetros adotados.

Fonte: Autores (2020). 


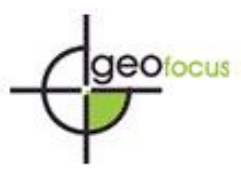

Guerrero, JVR, Moschini, LE., Chaves, MED., Mataveli, GAV., Morato, RG, Kawakubo, FS. (2020). Abordagem GEOBIA para a análise da dinâmica do uso da terra e cobertura vegetal no município de Brotas-SP, Brasil. GeoFocus, Revista Internacional de Ciencia y Tecnología de la Información Geográfica, 26, 21-41. http://dx.doi.org/10.21138/GF.675

Os resultados finais das segmentações de 2001 e 2016 são apresentados na Figura 3. A segmentação final se mostrou bastante representativa dos limites das classes permitindo diferenciar de maneira evidente a diversidade de uso da terra e cobertura vegetal presente em cada imagem. A Tabela 2 descreve o número de polígonos gerados para cada segmentação, bem como a estatística descritiva dos polígonos gerados.

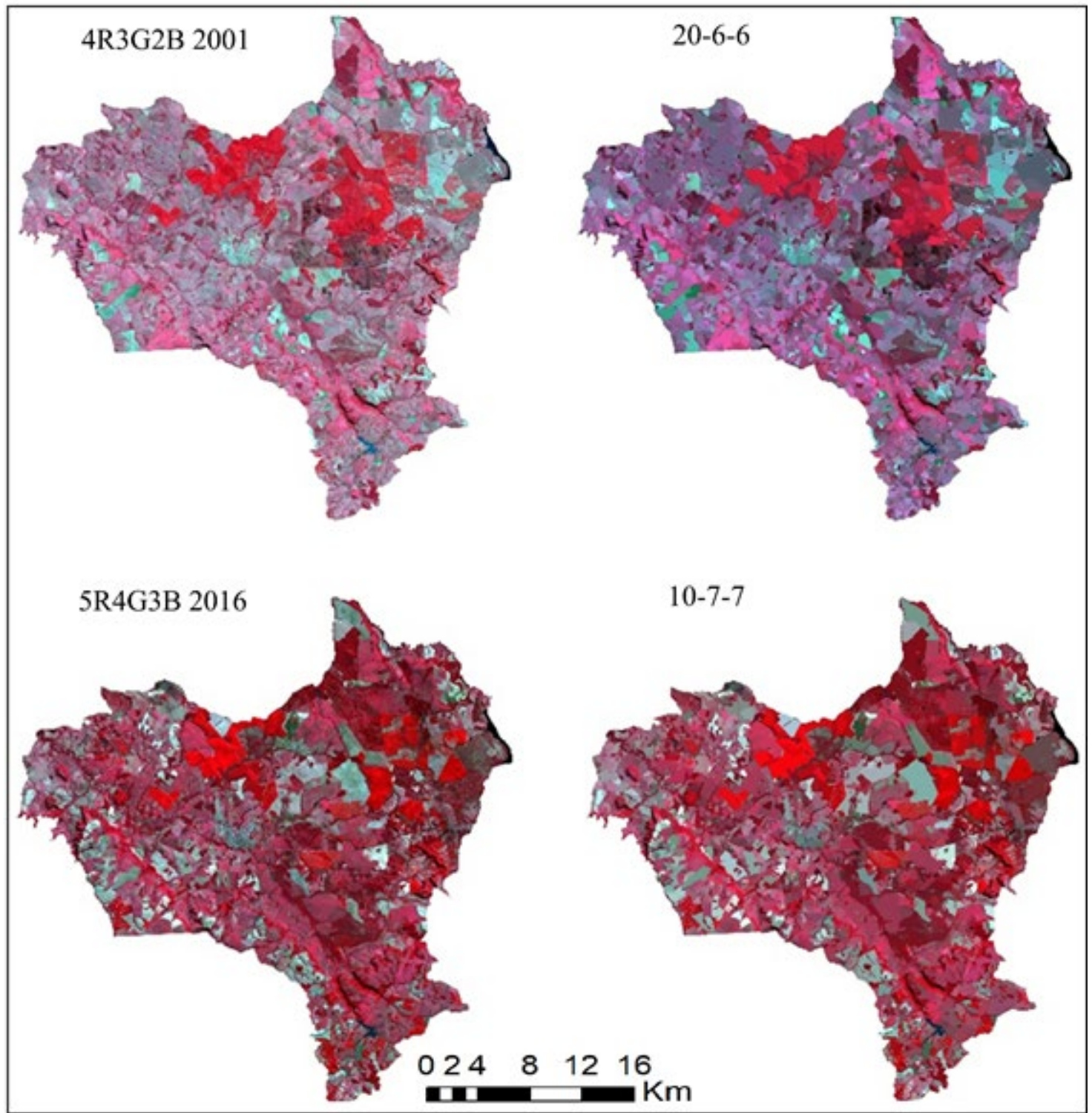

Figura 3. Resultado final das segmentações para os anos de 2001 e 2016 após os testes e a aplicação do método proposto.

Fonte: Autores (2020). 
Guerrero, JVR, Moschini, LE., Chaves, MED., Mataveli, GAV., Morato, RG, Kawakubo, FS. (2020). Abordagem GEOBIA para a análise da dinâmica do uso da terra e cobertura vegetal no município de Brotas-SP, Brasil. GeoFocus, Revista Internacional de Ciencia y Tecnología de la Información Geográfica, 26, 21-41. http://dx.doi.org/10.21138/GF.675

Tabela 2. Propriedades estatísticas dos polígonos gerados pelas segmentações.

\begin{tabular}{cccccc}
\hline Ano & Polígonos & Mínimo $\left(\mathrm{km}^{2}\right)$ & Máximo $\left(\mathrm{km}^{2}\right)$ & Média $\left(\mathrm{km}^{2}\right)$ & Moda $\left(\mathrm{km}^{2}\right)$ \\
\hline 2001 & 59.910 & 0,0001 & 8,1 & 0,37 & 0,0009 \\
2016 & 63.657 & 0,0001 & 9,0 & 0,39 & 0,0009 \\
\hline
\end{tabular}

Fonte: Autores (2020).

A segmentação de 2001 gerou 59.910 polígonos, com média de $0,37 \mathrm{~km}^{2}$ de área para cada um deles e tamanho máximo de $8,1 \mathrm{~km}^{2}$. Para a imagem de 2016, o número de polígonos aumentou para 63.657, com média de $0,39 \mathrm{~km}^{2}$ e tamanho máximo de $9 \mathrm{~km}^{2}$, o que mostra o processo de fragmentação da paisagem ocorrido durante o período analisado. Tais valores são compatíveis com os encontrados por Mataveli et al. (2019), que obtiveram resultados satisfatórios ao analisar o uso e cobertura da terra no município de Extrema (Brasil) com o uso de GEOBIA. Estes valores são consequência dos parâmetros utilizados para detectar a heterogeneidade do uso da terra e cobertura vegetal em Brotas, e indicam que o contexto espacial local é formado por pequenas propriedades e talhões pequenos e parcelados. Sem o ajuste adequado de parâmetros, este tipo de ocupação, ligado ao parcelamento derivado de atividades agrossilvipastoris, pode provocar a agregação espacial de diferentes alvos, causando a formação de geo-objetos mistura espectral (Lebourgeouis et al. 2017; Watkins \& Van Niekerk 2019). Com o uso de parâmetros para considerar características que vão além da informação espectral, como a forma, a textura, a compacidade e as relações de vizinhança, tal problema foi evitado.

\subsection{Classificação do uso da terra e cobertura vegetal}

Conforme a proposição metodológica, foram produzidas duas cartas de uso da terra e cobertura vegetal do município de Brotas, que são apresentadas na Figura 4.

A análise da classificação do uso da terra e cobertura vegetal do ano de 2001 revelou que a principal classe encontrada à época foi a "Agrícola", que incluía culturas agrícolas como cana-deaçúcar, milho, laranja e café, bem como solos preparados para cultivo, totalizando $50,8 \%$ da área total do município. De acordo com o histórico do contexto de produção agrícola municipal, essas culturas já representavam a base da agricultura local em 2001, sendo, nesta ordem, as culturas com maior produção em toneladas (IBGE 2020). A segunda classe de maior expressão em 2001 foi a de "Campo/Pastagem", classe de uso da terra com relevante grau de intervenção antrópica e características fenológicas semelhantes (IBGE 2012). Ressalta-se que a atividade pecuária também tem relevância na provisão de divisas econômicas ao município de Brotas, porém, em menor escala que a agricultura (IBGE 2020). As outras classes detectadas à época foram "Mata", que se encontrava bastante fragmentada, como reflexo da diminuição da área florestada entre o século XIX e a primeira metade do século XX, em função da expansão das pastagens e da ocupação do café (Chiarini \& Coelho 1969), "Eucalipto", com área destacada para a época, "Área Urbana" e "Solo Exposto", mesmo que em menor escala. 


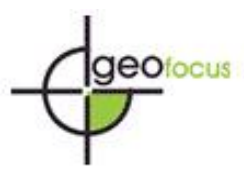

Guerrero, JVR, Moschini, LE., Chaves, MED., Mataveli, GAV., Morato, RG, Kawakubo, FS. (2020). Abordagem GEOBIA para a análise da dinâmica do uso da terra e cobertura vegetal no município de Brotas-SP, Brasil. GeoFocus, Revista Internacional de Ciencia y Tecnología de la Información Geográfica, 26, 21-41. http://dx.doi.org/10.21138/GF.675

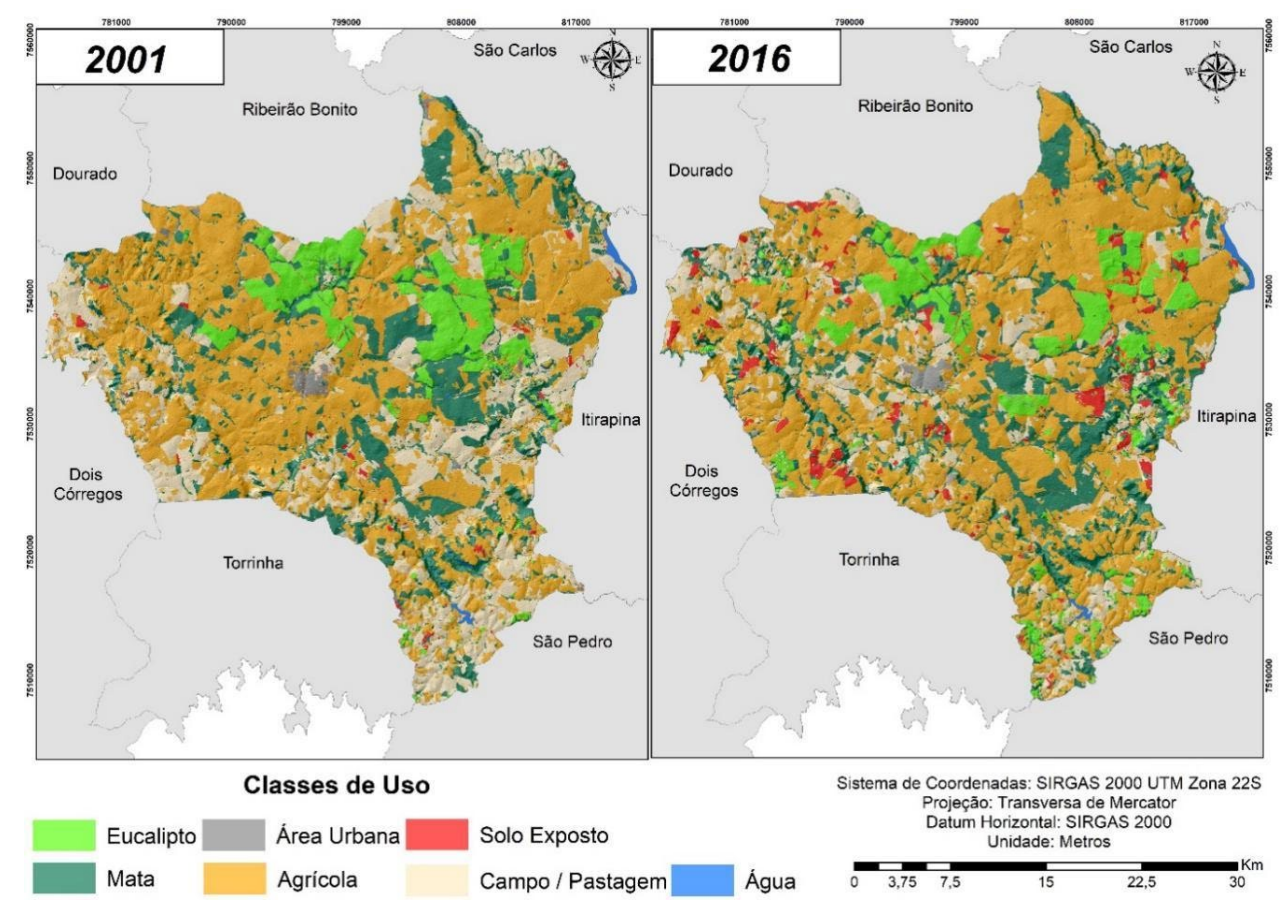

Figura 4. Classificações de uso da terra e cobertura vegetal do município de Brotas-SP, referentes aos anos de 2001 e 2016.

Fonte: Autores (2020).

A análise referente ao ano de 2016 também revelou o predomínio da classe "Agrícola", que passou a contemplar $52,16 \%$ da área total municipal. Analisando as estatísticas de produção agrícola municipal (IBGE 2020), constata-se que as culturas de cana-de-açúcar, milho, laranja e café se mantiveram como as mais plantadas. A segunda maior classe passou a ser "Mata", com $20 \%$ da área total municipal (acréscimo de 4,1\% em relação ao ano de 2001). Este incremento é um forte indicativo da eficácia dos programas ambientais no município e da conscientização de que o serviço ecossistêmico provido pela mata nativa é importante. Outras classes que apresentaram incremento foram "Solo exposto" (2,7\%) e "Eucalipto" (0,3\%). Por sua vez, "Área Urbana" e "Água" permaneceram estáveis.

O desempenho da classificação em 2001 foi considerado satisfatório para todas as classes mapeadas, obtendo exatidões do usuário e do produtor acima de $85 \%$, com exceção da classe Campo/Pastagem que apresentou exatidão do produto de $76 \%$ (Tabela 3). Apesar das confusões existentes, os resultados indicam exatidão global de $92 \%$ e índice Kappa de 0,90, valores com os quais a classificação pode ser considerada satisfatória, dentro dos padrões propostos por Landis \& Koch (1992) para a avaliação de mapeamentos. 
Guerrero, JVR, Moschini, LE., Chaves, MED., Mataveli, GAV., Morato, RG, Kawakubo, FS. (2020). Abordagem GEOBIA para a análise da dinâmica do uso da terra e cobertura vegetal no município de Brotas-SP, Brasil. GeoFocus, Revista Internacional de Ciencia y Tecnología de la Información Geográfica, 26, 21-41. http://dx.doi.org/10.21138/GF.675

Tabela 3. Matriz de erros da classificação do uso da terra e cobertura vegetal em 2001.

\begin{tabular}{crrrrrrrrr}
\hline $\begin{array}{c}\text { Referência } \rightarrow \\
\text { Classificação } \\
\downarrow\end{array}$ & $\begin{array}{c}\text { Área } \\
\text { Urbana }\end{array}$ & Mata & Agrícola & $\begin{array}{c}\text { Campo/ } \\
\text { Pastagem }\end{array}$ & Água & $\begin{array}{c}\text { Solo } \\
\text { Exposto }\end{array}$ & Eucalipto & Total & $\begin{array}{c}\text { EU } \\
(\%)\end{array}$ \\
\hline Área Urbana & $\mathbf{4 3}$ & 0 & 0 & 7 & 0 & 0 & 0 & 50 & 86 \\
Mata & 0 & $\mathbf{4 6}$ & 3 & 1 & 0 & 0 & 0 & 50 & 92 \\
Agrícola & 0 & 2 & $\mathbf{4 3}$ & 5 & 0 & 0 & 0 & 50 & 86 \\
Campo/ & 1 & 2 & 2 & $\mathbf{4 5}$ & 0 & 0 & 0 & 50 & 90 \\
Pastagem & 0 & 0 & 0 & 0 & $\mathbf{5 0}$ & 0 & 0 & 50 & 100 \\
Água & 2 & 1 & 0 & 1 & 0 & $\mathbf{4 6}$ & 0 & 50 & 92 \\
Solo Exposto & 0 & 1 & 0 & 0 & 0 & 0 & $\mathbf{4 9}$ & 50 & 98 \\
Eucalipto & 46 & 52 & 48 & 59 & 50 & 46 & 49 & 350 & - \\
Total & 93 & 88 & 89 & 76 & 100 & 100 & 100 & - & - \\
EP (\%) & & & & & & & & & \\
\hline
\end{tabular}

$\mathrm{EU}=$ Exatidão do usuário; $\mathrm{EP}=$ Exatidão do produtor. Confiabilidade média $=92 \%$, exatidão média $=92 \%$, exatidão global $=92 \%$ e Kappa $=0,90$.

Fonte: Autores (2020).

Com relação ao mapeamento da imagem referente ao ano de 2016, o desempenho da classificação também foi satisfatório, porém, os valores de acurácia foram menores em relação à imagem de 2001 (Tabela 4). A classe Agrícola obteve a menor exatidão do produtor (70 \%) provavelmente em razão da maior diversidade espectral dos cultivos. Assim como na classificação do ano de 2001, as maiores confusões foram observadas envolvendo áreas agrícolas e os campos/pastagens. O valor de exatidão global foi de $89 \%$ e o coeficiente Kappa foi de 0,89 , estando, portanto, no mesmo intervalo de concordância da classificação de 2001 nos padrões propostos por Landis \& Koch (1992). 
Guerrero, JVR, Moschini, LE., Chaves, MED., Mataveli, GAV., Morato, RG, Kawakubo, FS. (2020). Abordagem GEOBIA para a análise da dinâmica do uso da terra e cobertura vegetal no município de Brotas-SP, Brasil. GeoFocus, Revista Internacional de Ciencia y Tecnología de la Información Geográfica, 26, 21-41. http://dx.doi.org/10.21138/GF.675

Tabela 4. Matriz de erros da classificação do uso da terra e cobertura vegetal em 2016.

\begin{tabular}{|c|c|c|c|c|c|c|c|c|c|}
\hline $\begin{array}{c}\text { Referência } \\
\rightarrow \\
\text { Classificação } \\
\downarrow\end{array}$ & $\begin{array}{c}\text { Área } \\
\text { Urbana }\end{array}$ & Mata & Agrícola & $\begin{array}{c}\text { Campo/ } \\
\text { Pastagem }\end{array}$ & Água & $\begin{array}{c}\text { Solo } \\
\text { Exposto }\end{array}$ & Eucalipto & Total & $\begin{array}{l}\text { EU } \\
(\%)\end{array}$ \\
\hline $\begin{array}{l}\text { Área } \\
\text { Urbana }\end{array}$ & 45 & 1 & 3 & 1 & 0 & 0 & 0 & 50 & 90 \\
\hline Mata & 0 & 44 & 5 & 0 & 0 & 0 & 1 & 50 & 88 \\
\hline Agrícola & 0 & 3 & 43 & 4 & 0 & 0 & 0 & 50 & 86 \\
\hline $\begin{array}{c}\text { Campo/ } \\
\text { Pastagem }\end{array}$ & 0 & 2 & 4 & 44 & 0 & 0 & 0 & 50 & 88 \\
\hline Água & 0 & 1 & 1 & 0 & 48 & 0 & 0 & 50 & 96 \\
\hline $\begin{array}{c}\text { Solo } \\
\text { Exposto }\end{array}$ & 0 & 1 & 5 & 2 & 0 & 42 & 0 & 50 & 84 \\
\hline Eucalipto & 0 & 0 & 0 & 2 & 0 & 0 & 48 & 50 & 96 \\
\hline Total & 45 & 52 & 61 & 53 & 48 & 42 & 48 & 350 & - \\
\hline EP (\%) & 100 & 84 & 70 & 83 & 100 & 100 & 100 & - & - \\
\hline
\end{tabular}

$\mathrm{EU}=$ Exatidão do usuário; $\mathrm{EP}=$ Exatidão do produtor. Confiabilidade média $=92 \%$, exatidão média $=92 \%$, exatidão global $=89 \%$ e Kappa $=0,89$.

Fonte: Autores (2020).

3.3. Análise comparativa das classificações do uso e cobertura da terra em 2001 e 2016

A análise comparativa dos resultados das duas classificações de uso da terra e cobertura vegetal torna possível afirmar que não houve alteração na ordem da predominância das classes mapeadas, porém, ocorreram alterações significativas na área ocupada por algumas classes diretamente ligadas às atividades econômicas que geram divisas ao município (Tabela 5).

Tabela 5. Área total e percentual de cada uso da terra e cobertura vegetal e mudanças nas classes de uso e cobertura entre as classificações de 2001 e 2016.

\begin{tabular}{crrrrr}
\hline Classes & \multicolumn{2}{c}{ Área ocupada $\left(\mathrm{km}^{2}\right)$} & \multicolumn{2}{c}{ Área ocupada $(\%)$} & Mudanças (\%) \\
& 2001 & 2016 & 2001 & 2016 & $+0,1$ \\
Urbano & 8,1 & 8,9 & 0,7 & 0,8 & $+4,1$ \\
Mata & 175 & 221 & 15,9 & 20 & $+1,2$ \\
Agrícola & 560 & 572 & 50,8 & 52 & $-8,6$ \\
Campo/Pastagem & 247 & 157 & 22,6 & 14,1 & $+2,7$ \\
Solo Exposto & 9 & 38 & 0,8 & 3,5 & $+0,3$ \\
Eucalipto & 95 & 98 & 8,6 & 9 & 0 \\
Água & 7 & 7 & 0,6 & 0,6 &
\end{tabular}


Guerrero, JVR, Moschini, LE., Chaves, MED., Mataveli, GAV., Morato, RG, Kawakubo, FS. (2020). Abordagem GEOBIA para a análise da dinâmica do uso da terra e cobertura vegetal no município de Brotas-SP, Brasil. GeoFocus, Revista Internacional de Ciencia y Tecnología de la Información Geográfica, 26, 21-41. http://dx.doi.org/10.21138/GF.675

A diferença mais expressiva foi a redução nas áreas de "Campo/Pastagem" (de 22 \% para 14 \%), alteração que pode ser explicada por fatores diametralmente opostos, ligados tanto ao avanço da agricultura, quanto ao já consolidado processo de restauração florestal no município. Essas vertentes ambivalentes estão incorporando áreas anteriormente destinadas a pastos. $\mathrm{O}$ fator que impulsiona essa incorporação é a atual maior valoração econômica dessas áreas para agricultura do que para recuperação ambiental (Rudorff et al. 2010).

Em relação à conversão para a classe "Agricultura", os cultivos agrícolas tiveram sua área aumentada em 1,2\%, passando de $560 \mathrm{~km}^{2}$ para $572 \mathrm{~km}^{2}$. Esse aumento é reflexo da expansão da atividade no estado de São Paulo, com destaque para a cana-de-açúcar. A atividade de silvicultura "Eucalipto" também teve sua área aumentada $(0,3 \%)$, aproveitando a expansão do plantio de eucalipto no Brasil no início do século XXI para o abastecimento da indústria madeireira e a extração de celulose (Gonçalves et al. 2016). Ao passo em que houve decréscimo em áreas de "Campo/Pastagem", esses resultados permitem inferir que a atividade agrícola se expandiu, prioritariamente, sobre áreas de pastagem. Silva et al. (2016) consideram que o avanço da agricultura tende a ser maior em curto prazo, e que isso pode afetar áreas que deveriam ser restauradas. Nesta linha, Manzione et al. (2016) consideram que o avanço do eucalipto sobre áreas de pastagem na área de estudo merece atenção, dada a maior drenagem de água do aquífero Guarani, fator que vem reduzindo os níveis de água do manancial nos últimos anos. $\mathrm{O}$ aquífero, inclusive, tem ficado mais exposto a contaminações diante da conversão para tais atividades (Guerrero et al. 2017).

As pastagens constituem o uso da terra que mais tem perdido área no estado de São Paulo (Rudorff et al. 2010), devido à baixa remuneração do setor pecuário nas últimas décadas, o aumento do preço das terras paulistas e as pressões do setor sucroenergético para aumento das áreas de canade-açúcar (Ronquim et al. 2014; Ronquim et al. 2015). Em regiões como a do município de Brotas, onde o setor sucroalcooleiro é predominante, a maior parte da área cedida pelas pastagens é incorporada pela cultura da cana-de-açúcar (Ronquim et al. 2014; 2015).

Em relação à conversão para áreas de mata, embora a conversão de pastagem para agricultura, de forma majoritária, diminua a área útil para a expansão da vegetação florestal, observa-se que as áreas correspondentes à classe Mata apresentaram incremento de $4,1 \%$, reflexo da adoção de políticas ambientais do município de Brotas para reaver os serviços ecossistêmicos perdidos e valorizar o turismo ecológico no local. O principal fator para o acréscimo em áreas de mata está relacionado com a forma como o município de Brotas se apresenta como estância turística ecológica, decorrente dos seus atributos naturais (Ronquim et al. 2018). Ehlers (2007) pontua que, em geral, novos empreendimentos e oportunidades de trabalho ligados ao meio ambiente são criados em função da possibilidade de um relacionamento mais próximo à natureza, visando um crescimento menos destrutivo, mais duradouro e sustentável.

Dessa forma, quando o potencial econômico de uma área está relacionado aos seus atributos físicos e ecológicos, como no caso de Brotas, a preservação das áreas naturais relaciona-se e é incentivada pela própria manutenção da atividade turística e dos seus benefícios à economia e ao desenvolvimento local e regional (Trevisan et al. 2017). Analisando o entorno do município, o cenário de recuperação de áreas verdes ao longo dos anos é peculiar à Brotas e foge à realidade dos municípios vizinhos, que vêm enfocando suas diretrizes econômicas em processos tradicionais que beneficiam o aumento de áreas agrossilvipastoris em detrimento à conservação das matas nativas (Trevisan et al. 
Guerrero, JVR, Moschini, LE., Chaves, MED., Mataveli, GAV., Morato, RG, Kawakubo, FS. (2020). Abordagem GEOBIA para a análise da dinâmica do uso da terra e cobertura vegetal no município de Brotas-SP, Brasil. GeoFocus, Revista Internacional de Ciencia y Tecnología de la Información Geográfica, 26, 21-41. http://dx.doi.org/10.21138/GF.675

2018). Outro fator para o incremento da conversão de pastagem para mata em detrimento à área agrícola está relacionado à declividade. As florestas nativas em Brotas crescem principalmente nos terrenos declivosos que se localizam nas encostas das Cuestas basálticas, formação geológica que ocupa parte do município. As áreas são menos agricultáveis nessas condições de declividade, o que leva ao abandono da terra e ao retorno da vegetação florestal nativa (Silva et al. 2016).

O percentual de $20 \%$ de áreas de mata coloca Brotas, em termos proporcionais, em uma situação melhor que a de municípios paulistas que são considerados como estâncias turísticas por conta do ecoturismo, como Itu, que conta com apenas $8 \%$ de cobertura de mata (Prefeitura Municipal de Itu 2018) e Salto, com 9,4\% (Prefeitura Municipal de Salto 2017). Entretanto, em comparação a municípios considerados referências nacionais na implementação de políticas públicas voltadas à restauração ambiental, Brotas possui menos porcentagem de áreas de mata que Extrema-MG, com 44 \% (Mataveli et al. 2018) e Bonito-MS, com 48,9\% (Ronquim et al. 2018). Essa discrepância representa que o investimento na restauração dos remanescentes florestais deve ser aumentado caso o município vise atingir um patamar próximo ao de Extrema e Bonito na questão ambiental. Porém, os entraves políticos atrapalham já que as regras e responsabilidades para a recuperação da vegetação nativa ainda não foram definidas entre as esferas do governo (federal, estadual e municipal), a sociedade civil e o setor privado, e as políticas para tal são conflitantes entre instâncias governamentais, dificultando as ações estratégicas de planejamento e execução de melhorias ambientais relacionadas à essa temática (MMA 2017).

De acordo com Trevisan et al. (2017), o município dispõe de uma série de leis municipais como principais instrumentos para as questões ambientais, o que demonstra que os fatores legislativos relacionados ao planejamento municipal foram essenciais para que Brotas obtivesse avanços na restauração das áreas naturais. Porém, é notório que o ganho econômico com o ecoturismo, por exemplo, é um fator-chave para que o município observe a questão ambiental com mais cuidado. Isso sugere que políticas ambientais voltadas à recompensa financeira por ações que visem à conservação e restauração de recursos naturais sejam úteis para acelerar o processo de restauração ambiental, como tem ocorrido em Extrema-MG, por exemplo, com o Programa Conservador das Águas (Chiodi et al. 2013; Pacheco et al. 2017; Mataveli et al. 2018).

Em relação às outras classes de uso da terra e cobertura vegetal, um fator preocupante detectado nos dois mapeamentos foi o significativo aumento das áreas de solo exposto (de $0,8 \%$ para 3,5\%), algo relacionado à má gestão do solo derivada de práticas agrícolas inadequadas, que exaurem a terra com o passar do tempo. A maior exposição de solos aumenta, vertiginosamente, a fragilidade do local quanto a contaminações e processos erosivos, causadores de graves problemas ambientais, econômicos e sociais (Guerrero et al. 2016). Assim como observado por Silva et al. (2016), muitas áreas de pastagem e solo exposto estão localizadas no entorno dos cultivos agrícolas, e caracterizam solos com antiga utilização para o plantio e outras atividades antrópicas, que agora se deparam com degradação e erosão do solo. $\mathrm{O}$ aumento de solo exposto também pode ter sido causado pela diminuição da cobertura vegetal para proteger o solo e pelas condições de declividade do terreno, o que pode ter gerado processos erosivos; além do pisoteio de gado em algumas áreas da margem do ribeirão, fator que agrava o processo de assoreamento (Silva et al. 2016).

A Figura 5 ilustra as áreas que não sofreram alterações registradas nas imagens de 2001 e 2016, assim como as áreas de maiores alterações entre os anos considerados, com destaque para as que eram 


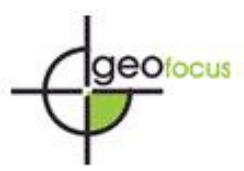

Guerrero, JVR, Moschini, LE., Chaves, MED., Mataveli, GAV., Morato, RG, Kawakubo, FS. (2020). Abordagem GEOBIA para a análise da dinâmica do uso da terra e cobertura vegetal no município de Brotas-SP, Brasil. GeoFocus, Revista Internacional de Ciencia y Tecnología de la Información Geográfica, 26, 21-41. http://dx.doi.org/10.21138/GF.675

ocupadas por atividades agrícolas em 2001 e que foram convertidas para Campo/Pastagem e Mata e as áreas antes ocupadas pela classe Campo/Pastagem que se tornaram Agricultura em 2016.
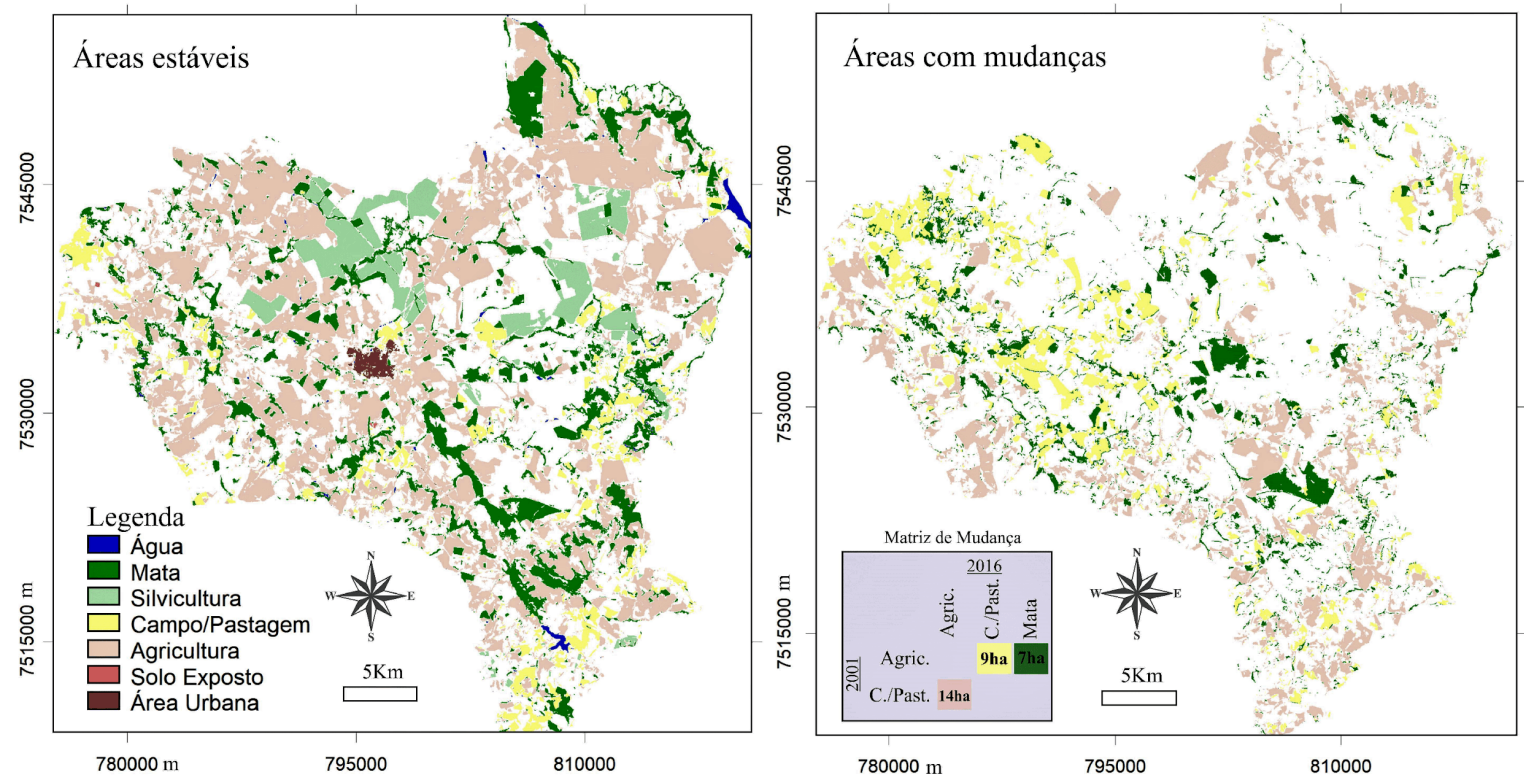

Figura 5. Áreas estáveis e que sofreram mudanças no uso e cobertura vegetal de Brotas entre 2001 e 2016

Fonte: Autores (2020).

Apesar de pequeno, o crescimento da classe "Área Urbana" pode ser explicado pelo aumento demográfico ocorrido entre as datas de estudo, que ocorreu na taxa de $14 \%$ (IBGE, 2020). Por fim, não foram registradas alterações na classe "Água" (representadas por rios, lagos, açudes e represas) o que denota que os problemas ambientais não causaram assoreamento dos cursos d'água locais. Foi possível notar que os cursos d'água detectados foram margeados por fragmentos florestais remanescentes. Embora dispersos e sem correlação espacial, em decorrência do avanço das fronteiras agrícolas em algumas áreas, e, em outras, pela dificuldade de uso e ocupação devido ao relevo acidentado (Silva et al. 2016), eles ajudam a melhorar, inclusive, as condições do aquífero Guarani (CETESB 2014; Batista \& Gastmans 2015), importante fonte de abastecimento de água na região. A respeito do crescimento urbano pouco significativo nesse período, Trevisan et al. (2017) consideram que isso se deve ao município depender do setor agropecuário, fato que faz uma parcela da população permanecer na zona rural para trabalhar em atividades agrossilvipastoris.

\section{Conclusão}

A identificação das áreas de alteração ressalta, então, que apesar dos esforços municipais que culminaram em um aumento das áreas de mata, a conversão territorial em áreas agrícolas e de 
Guerrero, JVR, Moschini, LE., Chaves, MED., Mataveli, GAV., Morato, RG, Kawakubo, FS. (2020). Abordagem GEOBIA para a análise da dinâmica do uso da terra e cobertura vegetal no município de Brotas-SP, Brasil. GeoFocus, Revista Internacional de Ciencia y Tecnología de la Información Geográfica, 26, 21-41. http://dx.doi.org/10.21138/GF.675

pastagem ainda é uma realidade muito presente em Brotas, principalmente nas áreas mais planas e consequentemente de morfodinâmica mais estável.

Os resultados das classificações retratam as mudanças que levaram ao atual motor econômico do município, composto pela tradicional agricultura e pelo recente ecoturismo em detrimento a outras atividades, como a criação de gado. $\mathrm{O}$ aumento de $4,1 \%$ em áreas de mata indica que as políticas públicas adotadas têm refletido de forma positiva, demonstrando o comprometimento do município com a qualidade ambiental local. Todavia, ressalta-se que ocorreu de forma fragmentada, o que torna necessário aumentar a eficiência das políticas adotadas e atingir os avanços propostos nos planos ambientais do município. Da mesma maneira, o aumento de áreas agrícolas, condicionado, especialmente, pela expansão da cana-de-açúcar em nível estadual, exige atenção para que não seja extensivo e provoque a exaustão do solo, como ocorreu em outras áreas do próprio município. Sugerese a realização de estudos comparativos com outros municípios para avaliar a situação de Brotas nos níveis estadual e nacional.

A aplicação da abordagem GEOBIA para a segmentação de imagens e a classificação orientada a objeto foi eficiente para identificar as mudanças no uso da terra e cobertura vegetal, demonstrando exatidão média acima de $89 \%$. Como o intuito do trabalho foi investigar a eficiência dos programas ambientais adotados para a restauração florestal em Brotas, buscou-se um método que realçasse as áreas de mata, separando-as das classes que correspondem a usos antrópicos da superfície terrestre. A consequência disso foi a confusão entre as classes de pastagem e agricultura, o que não impediu as constatações feitas. Para trabalhos futuros, pretende-se mitigar as confusões entre essas classes com o uso de séries temporais de índices de vegetação de um período que corresponda aos ciclos fenológicos das culturas agrícolas, aumentando o grau de separabilidade entre esses alvos.

\section{Agradecimentos}

Os autores agradecem a Fundação de Amparo à Pesquisa do Estado de São Paulo (FAPESP) pela concessão de bolsa de Doutorado aportada ao processo 2016/19020-0 e Pós-Doutorado processo 2019/25701-8 e a Coordenação de Aperfeiçoamento de Pessoal de Nível Superior-Brasil (CAPES) Código de financiamento 001, Processo número 88887.351470/2019-00.

\section{Referências bibliográficas}

Álvares, C. A., Stape, J. L., Sentelhas, P. C., Gonçalves, J. L., Sparovek, G. (2013). Köppen 's Climate classification map for Brazil. Meteorologische Zeitschrift, 22, 711-728. https://dx.doi.org/10.1127/0941-2948/2013/0507.

Batista, L., Gastmans, D. (2015). Hidrogeoquímica e qualidade das águas superficiais na bacia do Alto Jacaré-Pepira (SP), Brasil. Pesquisas em Geociências, 42, 297-311. https://dx.doi.org/10.22456/1807-9806.78186.

Belgiu, M., Csillik, O. (2018). Sentinel-2 cropland mapping using pixel-based and object-based time weighted dynamic time warping analysis, Remote Sensing of Environment, 204, 509-523. https://dx.doi.org/10.1016/j.rse.2017.10.005. 


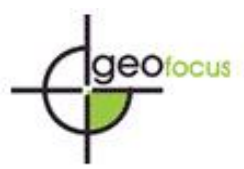

Guerrero, JVR, Moschini, LE., Chaves, MED., Mataveli, GAV., Morato, RG, Kawakubo, FS. (2020). Abordagem GEOBIA para a análise da dinâmica do uso da terra e cobertura vegetal no município de Brotas-SP, Brasil. GeoFocus, Revista Internacional de Ciencia y Tecnología de la Información Geográfica, 26, 21-41. http://dx.doi.org/10.21138/GF.675

Blaschke, T., Hay, G. J., Kelly, M., Lang, S., Hofmann, P., Addink, E., Feitosa, R. Q., van der Meer, F., van der Werff, H., van Coillie, F., Tiede, D. (2014). Geographic Object-Based Image Analysis Towards a new paradigm. ISPRS Journal of Photogrammetry and Remote Sensing, 87, 180-191. https://dx.doi.org/10.1016/j.isprsjprs.2013.09.014.

Carper, W. J., Lillesand, T. M. and Kiefer, R. W. (1990). The use of Intensity Hue Saturation transformations for merging SPOT panchromatic and multi-spectral image data. Photogrammetric Engineering and Remote Sensing, 56, 459-467.

Chaves, M. E. D., Picoli, M. C. A., Sanches, I. D. (2020). Recent Applications of Landsat 8/OLI and Sentinel-2/MSI for Land Use and Land Cover Mapping: A Systematic Review. Remote Sensing, 12(18), 3062. https://dx.doi.org/10.3390/rs12183062.

Chen, G., Hay, G. J., Carvalho, L. M. T., Wulder, M. A. (2012). Object-based change detection. International Journal of Remote Sensing, 33, 14, 4434-4457. https://dx.doi.org/10.1080/01431161.2011.648285.

Chiarini, J. V., Coelho, A. G. (1969). Cobertura vegetal natural do estado de São Paulo, Anuário Brasileiro de Ciências, 41, 139-152.

Chiodi, R. E., Puga, B. P., Sarcinelli, O. (2013). Análise institucional do mecanismo de pagamento por serviços ambientais: o Projeto Conservador das Águas em Extrema-MG. Revista de Políticas Públicas, 17, 1,37-47. https://dx.doi.org/10.18764/2178-2865.v17n1p37-47.

Companhia Ambiental do Estado de São Paulo - CETESB. (2014). Qualidade das Águas Superficiais no Estado de São Paulo, Parte 1: águas doces. São Paulo-SP, CETESB. [Consulta: 21-01-2020]. Disponível em: $<$ http://www.cetesb.sp.gov.br/agua/aguas-superficiais/35-publicacoes-/-relatorios $>$.

Congalton, R. G. (1991). A review of assessing the accuracy of classifications of remotely sensed data. Remote Sensing of Environment, 37, 35-46.

Csillik, O., Belgiu, M., Asner, G. P., Kelly, M. (2019). Object-based time-constrained Dynamic Time Warping classification of crops using Sentinel-2. Remote Sensing, 11, 10, 1257. https://dx.doi.org/10.3390/rs11101257.

de Oliveira, G., Chen, J. M., Mataveli, G. A. V., Chaves, M. E. D., Seixas, H. T., Cardozo, F. S., Shimabukuro, Y. E., He, L., Stark, S. C., dos Santos, C. A. C. (2020). Rapid Recent Deforestation Incursion in a Vulnerable Indigenous Land in the Brazilian Amazon and Fire-Driven Emissions of Fine Particulate Aerosol Pollutants. Forests, 11, 829. https://dx.doi.org/10.3390/f11080829.

Ehlers, E. (2007). Empreendedorismo e conservação ambiental no interior de São Paulo. Revista de Economia e Sociologia Rural, 45, 1, 185-203. https://dx.doi.org/10.1590/S010320032007000100009.

Environmental Systems Research Institute - ESRI. (2016). Segment MeanShift: Tutorial. [Consulta: 29-01-2020]. Disponível em: <http://desktop.arcgis.com/en/arcmap/10.3/tools/spatial-analysttoolbox/segment-mean-shift.htm>. 


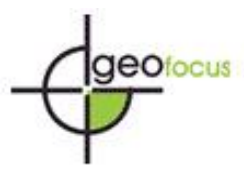

Guerrero, JVR, Moschini, LE., Chaves, MED., Mataveli, GAV., Morato, RG, Kawakubo, FS. (2020). Abordagem GEOBIA para a análise da dinâmica do uso da terra e cobertura vegetal no município de Brotas-SP, Brasil. GeoFocus, Revista Internacional de Ciencia y Tecnología de la Información Geográfica, 26, 21-41. http://dx.doi.org/10.21138/GF.675

Ferraz, S. F. B., Paula, S. R., Vettorazzi, C. A. (2009). Incorporação de indicadores de sustentabilidade na priorização de áreas para restauração florestal na Bacia do Rio Corumbataí, SP. Revista Árvore, 33, 5, 937-947. https://dx.doi.org/10.1590/S0100-67622009000500016.

Fukunaga, K., Hostetler, L. (1975). The estimation of the gradient of a density function, with applications in pattern recognition. IEEE Transactions on Information Theory, 21, 1, 32-40. https://dx.doi.org/10.1109/TIT.1975.1055330.

Ghassabeh, Y. A., Rudzicz, F. (2016). The mean shift algorithm and its relation to kernel regression. Information Sciences, 348, 198-208. https://dx.doi.org/10.1016/j.ins.2016.02.020.

Gonçalves, J. L. M., Álvares, C. A., Hubner, A., Junior, J. C. A. (2016). Caracterização edafoclimática e manejo de solos das áreas com plantações de eucalipto. In: Schumacher, M. V., Viera, M. (Ed.). Silvicultura do eucalipto no Brasil. $1^{\text {a }}$ ed. Santa Maria, Editora UFSM, p. 113-155.

Guerrero, J. V. R., Lollo, J. A., Lorandi, R. (2016). Cartografia geoambiental como base para planejamento territorial na bacia do rio Clarinho, SP. Revista Brasileira de Cartografia, 68, 2, 313326.

Guerrero, J. V. R., Chaves, M. E. D., Justino, R. C., Mataveli, G. A. V., Moschini, L. E. (2017). Potencial de contaminação de aquíferos na bacia do córrego do Gouveia, São Paulo. Acta Brasiliensis, 1(3), 1-7. https://doi.org/10.22571/Actabra13201757.

Guerrero, J. V. R., Escobar-Silva, E. V., Chaves, M. E. D., Mataveli, G. A. V., Bourscheidt, V., de Oliveira, G., Picoli, M. C. A., Shimabukuro, Y. E., Moschini, L. E. (2020). Assessing Land Use and Land Cover Changes in the Direct Influence Zone of the Braço Norte Hydropower Complex, Brazilian Amazonia. Forests, 11(9), 988. https://dx.doi.org/10.3390/f11090988.

Hay, G. J., Castilla, G. (2008). Geographic Object-Based Image Analysis (GEOBIA). A new name for a new discipline. In: Blaschke T., Lang S., Hay G.J. (eds.) Object-Based Image Analysis: Lecture Notes in Geoinformation and Cartography. Berlim, Springer, 75-89.

Instituto Brasileiro de Geografia e Estatística - IBGE. (2012). Manual Técnico da vegetação Brasileira. $2^{\mathrm{a}}$ ed. Brasília, Editora IBGE. [Consulta: 21-03-2020]. Disponível em: $<$ http://biblioteca.ibge.gov.br/visualizacao/livros/liv63011.pdf $>$.

Instituto Brasileiro de Geografia e Estatística - IBGE. (2020). Produção Agrícola Municipal - PAM.

Brasília, Editora IBGE. [Consulta: 21-03-2020]. Disponível em: $<$ https://sidra.ibge.gov.br/pesquisa/pam/tabelas $>$.

Instituto Brasileiro de Geografia e Estatística - IBGE. (2020). IBGE CIDADES - BROTAS. [Consulta: 21-03-2020]. Disponível em: <https://cidades.ibge.gov.br/brasil/sp/brotas/panorama> .

Jensen, J. R. (2009). Sensoriamento remoto do ambiente: uma perspectiva em recursos terrestres. Tradução de J.C.N. Epiphanio. São José dos Campos, Parêntese, 604.

Jiang, Z., Zhou, X., Knight, J., Corcoran, J. (2015). Focal-Test-Based Spatial Decision Tree Learning. IEEE Transactions on Knowledge and Data Engineering, 27, 6, 1547-1559. https://dx.doi.org/10.1109/TKDE.2014.2373383. 
Guerrero, JVR, Moschini, LE., Chaves, MED., Mataveli, GAV., Morato, RG, Kawakubo, FS. (2020). Abordagem GEOBIA para a análise da dinâmica do uso da terra e cobertura vegetal no município de Brotas-SP, Brasil. GeoFocus, Revista Internacional de Ciencia y Tecnología de la Información Geográfica, 26, 21-41. http://dx.doi.org/10.21138/GF.675

Köppen, W. (1936). Das Geographische System der Klimate. In: Köppen, W., Geiger, G. (Eds.). Handbuch der Klimatologie. Berlim, Gebrücker Borntraeger, 1-44.

Landis, R. J., Koch, G. G. (1977). The measurement of observer agreement for categorical data. Biometrics, 33, 159-174. https://dx.doi.org/10.2307/2529310.

Lebourgeois, V., Dupuy, S., Vintrou, É., Ameline, M., Butler, S., Bégué, A. (2017). A combined random forest and OBIA classification scheme for mapping smallholder agriculture at different nomenclature levels using multisource data (simulated Sentinel-2 time series, VHRS and DEM). Remote Sensing, 9, 3, 259. https://dx.doi.org/10.3390/rs9030259.

Lefebvre, A., Sannier, C., Corpetti, T. (2016). Monitoring Urban Areas with Sentinel-2A Data: Application to the Update of the Copernicus High Resolution Layer Imperviousness Degree. Remote Sensing, 8, 7, 606. https://dx.doi.org/10.3390/rs8070606.

Ma, L., Li, M., Ma, X., Cheng, L., Du, P., Liu, Y. (2017). A review of supervised object-based landcover image classification. ISPRS Journal of Photogrammetry and Remote Sensing, 130, 277-293. https://dx.doi.org/10.1016/j.isprsjprs.2017.06.001.

Manzione, R. L., Soldera, B. C., Wendland, E. C. (2016). Groundwater system response at sites with different agricultural land uses: case of the Guarani Aquifer outcrop area, Brotas/SP-Brazil. Hydrological Sciences Journal, 62, 28-35.https://dx.doi.org/10.1080/02626667.2016.1154148.

Mataveli, G. A. V., Guerrero, J. V. R., Chaves, M. E. D., Justino, R. C., Kawakubo, F. S., Morato, R. G. (2018). O Programa Conservador das Águas e sua Relação com o Uso da Terra em Extrema-MG. Revista do Departamento de Geografia, 36, 130-140. https://dx.doi.org/10.11606/rdg.v36i0.140424.

Ministério do Meio Ambiente - MMA. (2017). Plano Nacional de Recuperação da Vegetação Nativa - Planaveg. Brasília, Ministério do Meio Ambiente, 73 p.

Pacheco, B., Araujo, C. C. A. C. A., Filho, D. D. T., Santos, E. K. M. (2017). O Projeto Conservador das Águas: análise de uma política pública em Extrema/MG. Revista Brasileira de Desenvolvimento Regional, 5. 159-182. https://dx.doi.org/10.7867/2317-5443.2017v5n1p159-182.

Peixoto, C. A. B. (2010). Geodiversidade do estado de São Paulo. vol. 1. São Paulo: CPRM, 176.

Prefeitura Municipal de Brotas. (2006). Zoneamento Ambiental do Município de Brotas (SP): subsídios ao planejamento ambiental - relatório final. Brotas: Prefeitura Municipal de Brotas, 35.

Prefeitura Municipal de Brotas. (2016). Conheça Brotas. Brotas, Prefeitura Municipal de Brotas. [Consulta: 27-03-2020]. Disponível em <http://www.brotas.sp.gov.br/cidade/>.

Prefeitura Municipal de Itu. (2018). Plano municipal de conservação e recuperação da Mata Atlântica do municipio de Itu. Itu, Secretaria Municipal de Meio Ambiente. [Consulta: 27-03-2020]. Disponível em $\quad<$ https://itu.sp.gov.br/wp-content/uploads/2017/09/Plano-Municipal-deConserva $\%$ C3\%A7\%C3\%A3o-e-Recupera\%C3\%A7\%C3\%A3o-da-Mata-At1\%C3\%A2ntica.pdf $>$.

Prefeitura Municipal de Salto. (2017). Plano municipal de conservação e recuperação da Mata Atlântica da prefeitura da estância turística de Salto. Salto, Secretaria Municipal de Meio Ambiente. [Consulta: 27-03-2020]. Disponível em <http://www.agencia.baciaspcj.org.br/docs/legislacoes/saltopmcrma-2017.pdf $>$. 


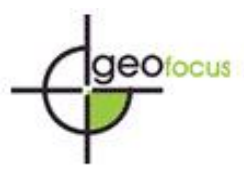

Guerrero, JVR, Moschini, LE., Chaves, MED., Mataveli, GAV., Morato, RG, Kawakubo, FS. (2020). Abordagem GEOBIA para a análise da dinâmica do uso da terra e cobertura vegetal no município de Brotas-SP, Brasil. GeoFocus, Revista Internacional de Ciencia y Tecnología de la Información Geográfica, 26, 21-41. http://dx.doi.org/10.21138/GF.675

Ronquim, C. C., Guilardi, V., Aguiar, D. A., Roque, A. A., Rudorff, B. F. T., Drugowich, M. I., Moreira, M. A. (2014). Avaliação geoespacial e socioeconômica da expansão das áreas de cana-deaçúcar sobre citros em municípios paulistas das bacias dos rios Mogi-Guaçu e Pardo entre 1988 e 2014. Série Documentos. Campinas, Embrapa Monitoramento por Satélite, 24.

Ronquim, C. C., Gonçalves, J. M., Guilardi, V., Garcon, E. A., Aguiar, D. A. (2015). Dinâmica de uso e cobertura da terra em áreas de produção de café e cana-de-açúcar em municípios paulistas das bacias dos rios Mogi-Guaçu e Pardo entre 1988 e 2015. Série Documentos. Campinas: Embrapa Monitoramento por Satélite, 28.

Ronquim, C. C., Rodrigues, C. A. G., Fonseca, M. F., Pinto, V. G. B. (2018). Dinâmica da mudança de uso e cobertura da terra e adequação ambiental dos municípios de Bonito (MS) e Brotas (SP). In: Simpósio de Geotecnologias no Pantanal, 7, 2018, Jardim, MS. Anais...São José dos Campos-SP: INPE; Campinas-SP: Embrapa, 481-490. [Consulta: 27-03-2020]. Disponível em: $<$ http://ainfo.cnptia.embrapa.br/digital/bitstream/item/185896/1/4984.pdf $>$.

Rudorff, B. F. T., Aguiar, D. A., Silva, W. F., Sugawara, L. M., Adami, M., Moreira, M. A. (2010). Studies on the rapid expansion of sugarcane for ethanol production in São Paulo State (Brazil) using Landsat data. Remote Sensing, 2, 4, 1057-1076. https://dx.doi.org/10.3390/rs2041057.

Silva, J. L., Tonello, K. C., Valente, R. A., Mingoti, R. (2016). Diagnóstico ambiental como subsídio à restauração florestal e manutenção hidrológica da bacia do ribeirão dos Pinheirinhos, Brotas - SP . Irriga , 21, 1, 1-13. https://dx.doi.org/10.15809/irriga.2016v21n1p1-13.

Silveira, E. M. O, Silva S. H. G., Acerbi-Junior, F. W., Carvalho, M. C., Carvalho, L. M. T., Scolforo, J. R. S., Wulder, M. A. (2019). Object-based random forest modelling of aboveground forest biomass outperforms a pixel-based approach in a heterogeneous and mountain tropical Environment. International Journal of Applied Earth Observation and Geoinformation, 78, 175-188. https://dx.doi.org/10.1016/j.jag.2019.02.004.

Swain, P. H., Davis, S. M. (1978). Remote sensing: the quantitative approach. New York: McGrawHill, 396.

Toure, S. I., Stow, D.A., Shis, H., Weeks, J., Lopez-Carr, D. (2018). Land cover and land use change analysis using multi-spatial resolution data and object-based image analysis. Remote Sensing of Environment, 210, 259-268.https://dx.doi.org/10.1016/j.rse.2018.03.023.

Trevisan D. P., Moschini L. E. (2015). Dinâmica de uso e cobertura da Terra em paisagem no interior do estado de São Paulo: Subsídios para o planejamento. Fronteiras: Journal of Social, Technological and Environmental Science, 4, 3, 16-30. https://dx.doi.org/10.21664/2238-8869.2015v4i3.p16-30.

Trevisan, D. P., Moschini, L. E., Guerrero, J. V. R. (2017). Dinâmica Temporal do Uso e Cobertura da Terra no Município de Brotas-SP entre os Anos de 1988 e 2016. Fronteiras: Journal of Social, Technological and Environmental Science, 6, 4, 204-219. https://dx.doi.org/10.21664/22388869.2017v6i4.p204-219.

United States Geological Survey - USGS. (2020). USGS Global Visualization Viewer (GloVis). [Consulta: 12-03-2020]. Disponível em <https://https://glovis.usgs.gov/>. 


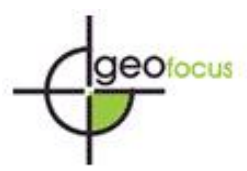

Guerrero, JVR, Moschini, LE., Chaves, MED., Mataveli, GAV., Morato, RG, Kawakubo, FS. (2020). Abordagem GEOBIA para a análise da dinâmica do uso da terra e cobertura vegetal no município de Brotas-SP, Brasil. GeoFocus, Revista Internacional de Ciencia y Tecnología de la Información Geográfica, 26, 21-41. http://dx.doi.org/10.21138/GF.675

Watkins, B., Van Niekerk, A. (2019). A comparison of object-based image analysis approaches for field boundary delineation using multi-temporal Sentinel-2 imagery. Computers and Electronics in Agriculture, 158, 294-302. https://dx.doi.org/10.1016/j.compag.2019.02.009.

Ye, S., Pontius, R. G., Rakshit, R. (2018). A review of accuracy assessment for object-based image analysis: From per-pixel to per-polygon approaches. ISPRS Journal of Photogrammetry and Remote Sensing, 141, 137-147. https://dx.doi.org/10.1016/j.isprsjprs.2018.04.002.

Yu, W., Weiqi, Z., Yuguo, Q., Jingli, Y. (2016). A new approach for land cover classification and change analysis: Integrating backdating and an object-based method. Remote Sensing of Environment, 177, 37-47. https://dx.doi.org/10.1016/j.rse.2016.02.030. 
